\title{
Developing a conceptual model for selecting and evaluating online markets
}

\author{
Sadegh Feizollahi $^{\mathbf{a}^{*}}$, Alireza Shirmohammadi ${ }^{\mathrm{b}}$ and Rohallah Hassani ${ }^{\mathrm{b}}$
}

${ }^{a}$ Department of Management, Mehran Branch, Islamic Azad University, Mehran, Iran

${ }^{b}$ Department of Industrial Management, Payam e noor University, PO BOX 19395-3697, Tehran, Iran

${ }^{c}$ Department of Management, Payam e noor University, PO BOX 19395-3697 Tehran, Iran

\section{H R O N I C L E

Article history:

Received October 20, 2012

Received in revised format

19 February 2013

Accepted 28 February 2013

Available online

March 12013

Keywords:

Conceptual models

Selecting and evaluating e-

commerce

Internet markets

\begin{abstract}
There are many evidences, which emphasis on the benefits of using new technologies of information and communication in international business and many believe that E-Commerce can help satisfy customer explicit and implicit requirements. Internet shopping is a concept developed after the introduction of electronic commerce. Information technology (IT) and its applications, specifically in the realm of the internet and e-mail promoted the development of ecommerce in terms of advertising, motivating and information. However, with the development of new technologies, credit and financial exchange on the internet websites were constructed so to facilitate e-commerce. The proposed study sends a total of 200 questionnaires to the target group (teachers - students - professionals - managers of commercial web sites) and it manages to collect 130 questionnaires for final evaluation. Cronbach's alpha test is used for measuring reliability and to evaluate the validity of measurement instruments (questionnaires), and to assure construct validity, confirmatory factor analysis is employed. In addition, in order to analyze the research questions based on the path analysis method and to determine markets selection models, a regular technique is implemented. In the present study, after examining different aspects of e-commerce, we provide a conceptual model for selecting and evaluating online marketing in Iran. These findings provide a consistent, targeted and holistic framework for the development of the Internet market in the country.
\end{abstract}

(c) 2013 Growing Science Ltd. All rights reserved.

\section{Introduction}

Nowadays, the Internet has penetrated into all aspects of our lives including social, political, cultural, etc. with dazzling speed. As soon as the world became familiar with the advantages of the primary internet features such as e-mail, people started to sophisticated applications including video and web chats. Besides, these technologies, services such as weblogs and established search engines were introduced. The software versions became outdated very rapidly and their more updated versions

Corresponding author.

(E-mail addresses: sadegh_feizollahi@yahoo.com (S.Feizollahi)

(C) 2013 Growing Science Ltd. All rights reserved.

doi: 10.5267/j.msl.2013.03.001 
were programmed and distributed and became available for downloading via internet for those interested. Many people all over the world hold information conferences and present their views to interested parties. Many online polls are now held in social and political domains and the results are immediately available on the web sites. The Internet has become the primary battlefield of business, economy and e-business. Internet marketing is one of the areas, which requires a model-oriented and principled programming. In this study, a conceptual model is presented for the selection and evaluation of Internet markets in Iran (Amaravadi et al., 1995).

\section{Literature review}

With an increase on the number of Internet users, usage of interactive tools as part of the decisions and actions of purchase has attracted many researchers and experts (Yazdanparast, 2008). Nearly $72 \%$ of Internet users search online at least once a month to look for various goods (Meuter et al., 2005). On the other hand, internal factors such as attitudes, habits and perceptions, affect consumers' willingness to buy online. The positive consumers shopping online behavior, therefore, can help online retailers survive and profit in a competitive market. There are different advantages for ecommerce advertising based on specific characteristics such as cultural, social and infrastructural characteristics and it is worth to see how e-commerce can make change in consumer behavior, customer satisfaction and business development. There are literally many advantages on information and communication technology and there are many reasons for using the recent advances on ecommerce in various countries (Soopramanien \& Robertson, 2007). Electronic commerce can be useful for various reasons, for instance, it provides easy access to products, which may not be possible to access them without internet. In addition, e-commerce is an easy way to perform transactions, and although it is sometimes more vulnerable than the traditional form, it can largely satisfy customers' needs (Budhiraja \& Sachdeva, 2002). With the rapid development of information technology and its entrance into everyday life, new problems and necessities have risen and new e-business has replaced traditional methods. Many studies demonstrate that success lies in preserving, maintaining and communicating with the customer (Svantesson \& Clarke , 2010). E-commerce is a new method of business by using electronic networks and the Internet. In this approach, any purchase or exchange of goods or services and information is possible via computer and communication networks including the Internet (Chaffey ,2002).

There are literally various definitions for e-commerce (Chaffey ,2002). According to Standing \& Graig (2009) e-commerce is defined as any buying or selling through the Internet networks. Ecommerce involves a variety of activities like electronic trading of goods and services, electronic funds transfer, electronic stock exchange, bill of lading, commercial designs, direct marketing and after-sales service.

In the business world, there are many barriers influencing decision and intention to purchase from web sites. Internet security deficiencies, lack of customer confidence to purchase virtually, website quality and its design model especially in the delivery of the related information and product will lead to unwillingness in customers. On the other hand, there are many other factors such as attitudes, habits, people's perception of environment and its opportunities for the customers (Olfat, 2012).

Market segmentation can be specified as the process of worldwide identification of potential customers such as individuals or countries, those with homogeneous characteristics, which tend to demonstrate similar purchase behavior. In the regular approach, several models have been proposed for the evaluation and selection of markets where they can be classified and presented as follows. These two classes of models, namely the models and patterns of identifying sectors and the models and patterns of selecting sectors are investigated in the following sections. Classification of regular models and patterns are presented as follows (Faraji \& Hojjat, 2006). According to Fig. 1, models and patterns of selecting sectors can be classified into market screening approach, sector criterion approach, portfolio management, competitive strategy and intelligent models. 


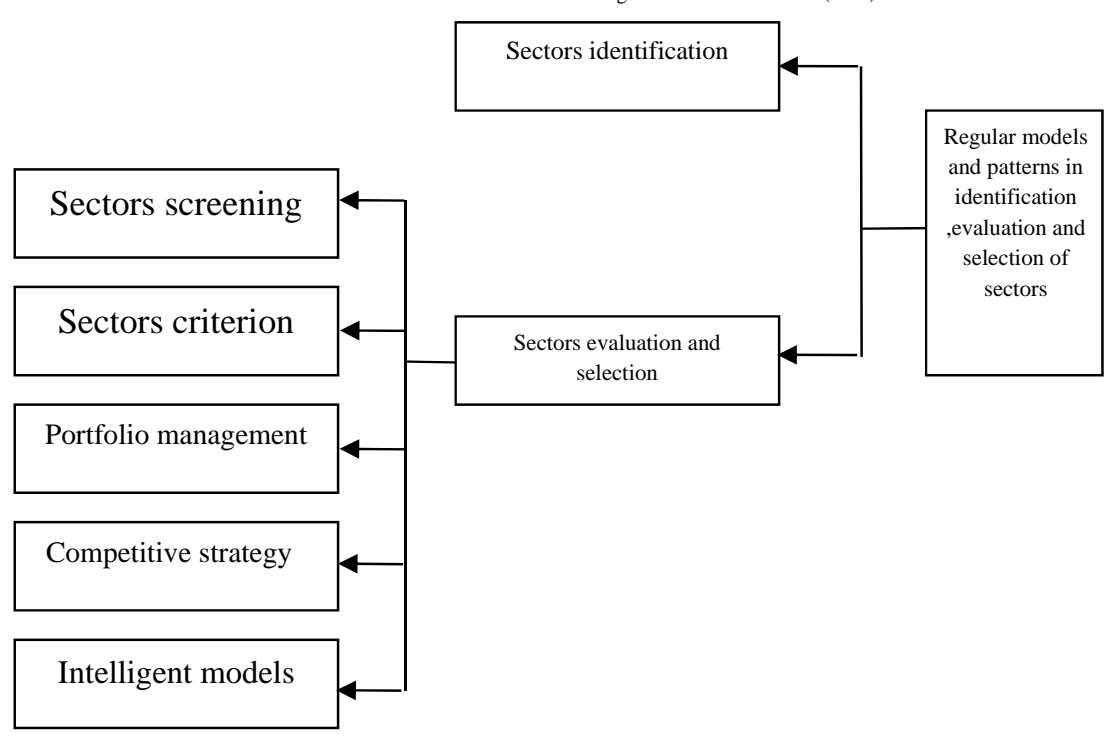

Fig.1. Classification of regular models and patterns

Market screening approach involves gathering information on various markets and screening them based on predefined criteria. In this approach, first using macro-level factors, a number of markets are selected, and then using the micro-level factors, a detailed market study of the screened markets will be conducted. Kumar and Stam (1993) described the overall process of screening in three stages of screening stage, identification and selection. The steps are performed orderly and in a slow manner. In the screening stage, the macro factors such as economic, legal, cultural and infrastructural factors are also taken into consideration. In the identification phase, having analyzed the information associated with industry, a list of markets is prepared. Assessment of the market growth rate, level of competition such as the type and number of competing products and their prices and barriers to entry such as tariffs, taxes, business income and allowances are factors that would be considered at this stage.

Finally, the data associated with the firm, including the firm's profitability and adapting product with the existing portfolio are considered. Among the criticisms of this approach is that by taking the national scope of the market, attention of decision makers will be drawn at the macro-economic and non-economic variables and considerations first, and maybe by using the first step of the screening process, the practical part of the customers are lost. Accordingly, the approach of screening might create a false impression of the true capacity of the firm to create a market for products. Sectors criterion approach includes the assessment of sector attractiveness taking into account and specific criteria are mainly accumulated from experimental studies. In this approach, after deriving indicators and criteria, certain weight is assigned to them, and various markets are evaluated based on a set of intended criteria (Poddar et al., 2009). In the meantime, Wood and Robertson (2000) Koch (2001) and Rahman (2003) only offered indicators of markets, but they did not propose a mechanism for the incorporation of information and the selection of target markets. The proposed models and patterns with respect to portfolio management focus on two factors, that is to say market attractiveness and the empowerment of strategic business unit (SBU). Among these models, we can mention Boston Consultant group matrix method, General Electric (GE) method, and Harrell and Kiefer model. These models do not consider planning horizon and it is not also possible to remove information stage in these models. In addition, in these models, a mechanism is not proposed for ordering and selecting of sectors and entry strategy into the sectors is not offered. Furthermore, with the primary focus of countries, it is also possible to segment target markets.

Another effective method to identify markets attractiveness is the industry analysis and the forces influencing it. A specific industry consists of a set of firms, where their manufactured products are close replacement of each other. The aim of competition in every industry is that the rate of 
investment returns closes to a rate obtained in conditions of perfect competition. The higher rates of investment returns encourage the investment flows from the new companies or existing competitors. According to a professor of Harvard university and well-known theorist of competiveness strategy, competiveness in every industry lies in five main forces. These forces include: 1 . Threat of new competition 2. Threat of substitute products or services 3. Bargaining power of customers (buyers) 4. Bargaining power of suppliers 5. Intensity of competitive rivalry. In fact, these forces and their interaction determine the competitive intensity and attractiveness of the market (industry). However, this model has been subject of much critiques, for example, this model does not take into consideration the access limitation and compatibility rates. In addition, this model does not present a mechanism for ordering and selecting of sectors. Using intelligent method, intelligent models try to create competitive intelligence (CI); to evaluate the attractiveness and the selection of target markets (Amaravadi, 1995). CI indicates create an intelligent system for the evaluation of competition structures, which enables the managers to be more effective and efficient against other competitors and special intelligence system refers to the analyzed information in the system. However, their model and Schwartz's model are general ones associated with the marketing and it does not specifically refer to the attractiveness of international markets. Lee's model only depends on a set of factors and the fitness to them and it does not show the necessary comprehensiveness. For instance, the limitations of access and the rate of the compatibility of marketing mix and process are not considered. Kim et al. (2010) in a research study the customers' perceptions of the website advertising and customer- stimulating factors to purchase from the internet shopping. Fig. 2 shows the model of this research.

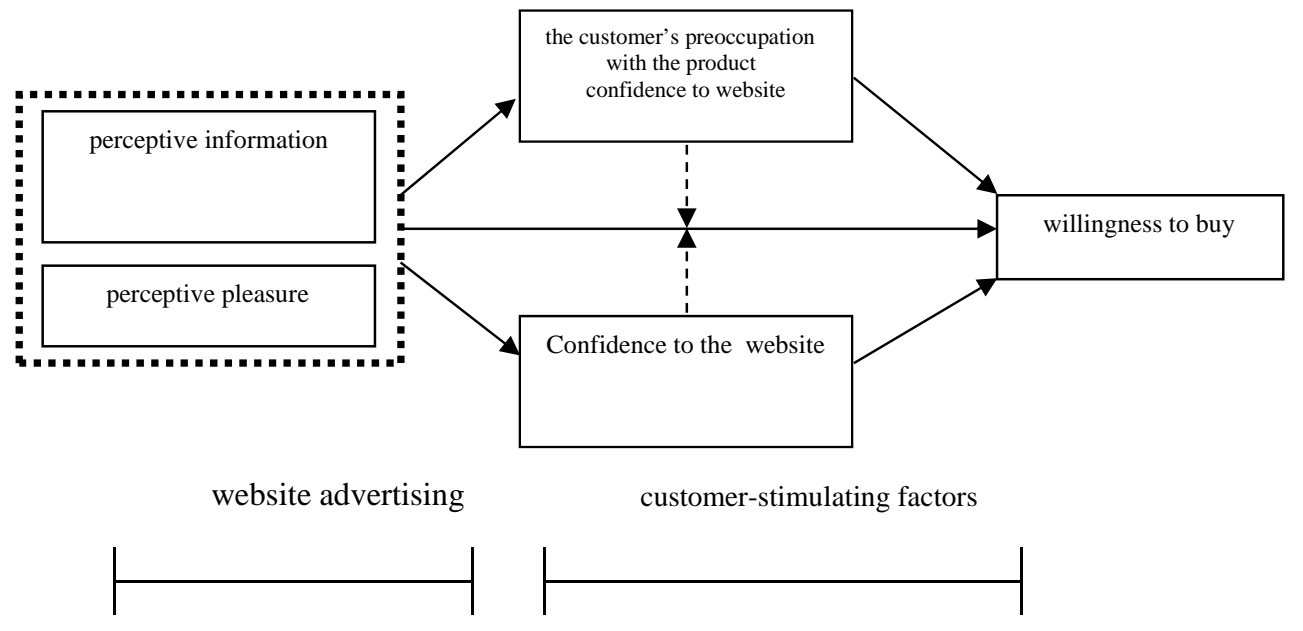

Fig. 2. Kim et al. model

According to this model, perceptive information strategy causes that the customer is preoccupied with one product and the relationship between these two variables is positive. On the other hand, there is a negative relationship between the perceptive pleasure and the customer's preoccupation with the new product. It is also proved that there is a direct relationship between the perceptive information and the perceptive pleasure with the confidence to the website.

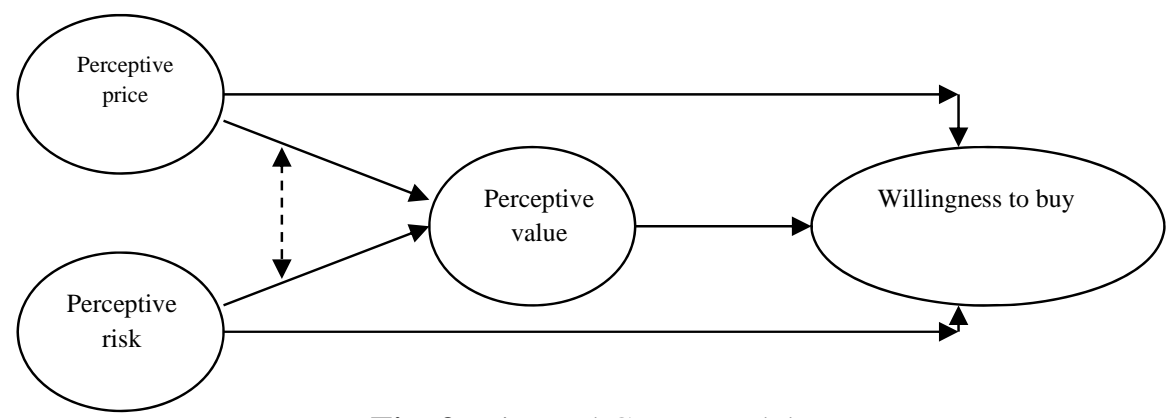

Fig. 3. Kim and Gupta model 
There is a mutual relationship between the confidence to the website and the customer's preoccupation with the product and this stimulates the customer to shop online. Poddar et al. (2009) proposed a model in which three variables, namely website identity, website quality and customer's intentions were recognized as the most influencing factors to shop online. Some other researchers examined the effective factors on internet shopping in two distinct categories; potential and actual customers. Hausman and Siekpe (2009) in a research study the effect of web interface features on consumer online purchase intentions.

\section{Materials and method}

This is an applied study because of its nature. To collect the data, library research and questionnaires were used. From a total of 200 questionnaires sent to the target group, teachers, students, professionals, managers of commercial web sites, 130 completed questionnaires were received and evaluated. To determine market selection models, there are two methods, namely the distribution (local) method and the regular (world standard) method. In this study, the regular method is applied. The regular models are categorized in two groups; the identification models and patterns of sectors and the selection models and patterns of sectors and in this study, we examine the second group of the regular patterns, the evaluation and the selection of sectors.

\subsection{Scales measurement}

Cronbach's alpha test was used for measuring the reliability of questionnaires. The obtained results showed that the Cronbach's alpha coefficient was 0.7768 confirming the reliability of the questionnaires. To evaluate the validity of measurement instruments and to assure construct validity, confirmatory factor analysis was used. Since the confirmatory factor analysis was analyzed in form of measuring model, in its results the goodness-of-fit test and validity of model were discussed and examined. The obtained results of instruments models for AGFI, GFI, RMSEA and Chi-Square are 0.82, 0.69, 0.019 and 700.04, respectively. This shows a small error in measurement and the obtained Chi-Square, 700.04, indicating the goodness-of-fit of the model. In order to answer research questions, path analysis method was used. If a model drawn in form of path diagram is confirmed by the goodness-of-fit indicators of the model, that diagram can be used to answer the questions about the casual relationship between the existing variables in path diagram. According to the research results, Fig. 4 is designed as the suggested model for selecting and evaluating of the internet markets.
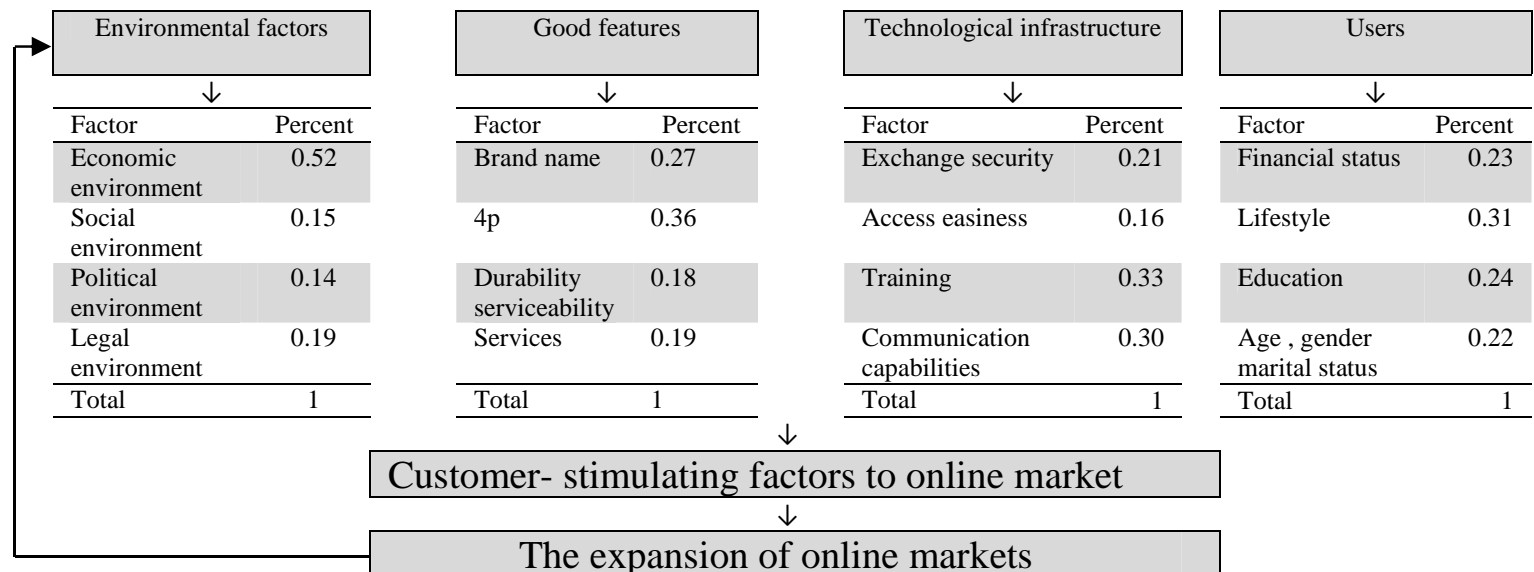

Communication $\quad 0.30$

capabilities

Total

\begin{tabular}{lr} 
Education & 0.24 \\
\hline $\begin{array}{l}\text { Age }, \text { gender } \\
\text { marital status }\end{array}$ & 0.22 \\
\hline Total & 1 \\
\hline
\end{tabular}

Customer- stimulating factors to online market

The expansion of online markets

Fig. 4. Conceptual model for selecting and evaluating online markets

\section{Results and Conclusion}

Based on the results of our investigation, four components including environmental factors, good features, technology infrastructure and users play significant role in selecting the internet market. 
Among environmental factors, economic factors with impact coefficient 0.52 and among good features, factors $4 \mathrm{P}$, price, place, product and promotion, with impact coefficient 0.36 have a considerable importance. In addition, educational factors with the impact coefficient of 0.33 and lifestyle with the impact coefficient of 0.31 in the realms of technology infrastructure and users (customers) respectively have prominent roles. In selecting and evaluating of internet markets, we need to take into consideration all factors and their components as well as their sub-unites. While having a holistic, coherent and consistent view of the type of the industry, market share, brand power, service ( good) features , customers' characteristics, infrastructures, folklore and etc. , Adjustments were made in order to fit more with the specific requirements of model coefficients and contingency of the industry.

\section{References}

Amaravadi, C. S., Samaddar, S., \& Dutta, S. (1995). Intelligent marketing information systems: computerized intelligence for marketing decision making. Marketing Intelligence \& Planning, 13(2), 4-13.

Budhiraja, R., \& Sachdeva, S. (2002). E-readiness assessment (India). On-line: http://unpan1. un. org/intradoc/groups/public/documents/APCITY/UNPAN014673. pdf.

Chaffey, D. (2007). E-business and e-commerce management: strategy, implementation and practice. Financial Times/Prentice Hall.

Crabbe, M., Standing, C., Standing, S., \& Karjaluoto, H. (2009). An adoption model for mobile banking in Ghana. International Journal of Mobile Communications, 7(5), 515-543.

Faraji Khorshidi, H. (2006) Designing an intelligent assessment of the attractiveness of international markets. Journal of Humanities, Tarbiat Modares University, Tehran [In Persian].

Hausman, A. V., \& Siekpe, J. S. (2009). The effect of web interface features on consumer online purchase intentions. Journal of Business Research, 62(1), 5-13.

Hsiao, M. H. (2009). Shopping mode choice: Physical store shopping versus e-shopping. Transportation Research Part E: Logistics and Transportation Review, 45(1), 86-95.

Kim, J. U., Kim, W. J., \& Park, S. C. (2010). Consumer perceptions on web advertisements and motivation factors to purchase in the online shopping.Computers in human behavior, 26(5), 1208-1222.

Koch, A. J. (2001). Selecting overseas markets and entry modes: two decision processes or one?. Marketing Intelligence \& Planning, 19(1), 65-75.

Kumar, V., Stam, A., \& Joachimsthaler, E. A. (1994). An interactive multicriteria approach to identifying potential foreign markets. Journal of International Marketing, 29-52.

Meuter, M. L., Bitner, M. J., Ostrom, A. L., \& Brown, S. W. (2005). Choosing among alternative service delivery modes: An investigation of customer trial of self-service technologies. Journal of Marketing, 6183.

Olfat, L.(2012).The identification and prioritization of the factors affecting online shopping. Journal of Business Management, Tehran University, 3(7).

Soto-Acosta, P., \& Meroño-Cerdan, A. L. (2009). Evaluating Internet technologies business effectiveness. Telematics and Informatics, 26(2), 211-221.

Poddar, A., Donthu, N., \& Wei, Y. (2009). Web site customer orientations, Web site quality, and purchase intentions: The role of Web site personality. Journal of Business Research, 62(4), 441-450.

Rahman, S.H. (2003). Modeling of international selection process: A qualitative study of successful Australian international business. Qualitative Market Research, 6(2), 119-132.

Wood, V. R., \& Robertson, K. R. (2000). Evaluating international markets: The importance of information by industry, by country of destination, and by type of export transaction. International Marketing Review, 17(1), 34-55.

Soopramanien, D. G., \& Robertson, A. (2007). Adoption and usage of online shopping: An empirical analysis of the characteristics of "buyers" "browsers" and "non-internet shoppers". Journal of Retailing and Consumer Services, 14(1), 73-82.

Svantesson, D., \& Clarke, R. (2010). A best practice model for e-consumer protection. Computer Law \& Security Review, 26(1), 31-37.

Yazdanparast Ardestani, A. (2008). Identification of factors influencing the attitudes of Iranian consumers towards shopping online or semi-online. MS Thesis, Department of Management and Accounting, Allameh Tabatabai University, Tehran 